\title{
Enlargement rate of geographic atrophy before and after secondary CNV conversion with associated anti-VEGF treatment
}

\author{
Jakob Siedlecki* ${ }^{*}$, Caroline Koch, Benedikt Schworm, Raffael Liegl, Thomas Kreutzer, Karsten U. Kortuem, \\ Ricarda Schumann, Siegfried G. Priglinger and Armin Wolf
}

\begin{abstract}
Background: To study the enlargement rate of primary geographic atrophy (GA) before and after diagnosis of a secondary choroidal neovascularization (CNV) treated with anti-vascular endothelial growth factor (VEGF) therapy.

Methods: Five hundred twenty-two consecutive eyes with primary GA were screened for the development of a complicating secondary CNV. Geographic atrophy was measured on blue autofluorescence (BAF) by two readers and calculated into mean growth rate before and after CNV diagnosis.

Results: Ten eyes of six patients were included in the study (six study eyes with GA complicated by CNV, four GA only partner eyes). Follow-up was $1.42 \pm 0.48$ years before and $3.64 \pm 2.73$ years after CNV. There was no significant difference between mean growth rate before and after CNV (1.58 \pm 0.99 vs. $1.39 \pm 0.65 \mathrm{~mm}^{2} /$ year; $\left.p=0.44\right)$ or between study and partner eyes ( $p=0.86$ ). Over a mean time of $3.64 \pm 2.73$ years, a mean of $8.3 \pm 2.8$ anti-VEGF injections were given. No correlation between the amount of anti-VEGF injections and change in growth rate could be observed $(r=0.58 ; p=0.23)$.

Conclusion: In this pilot study, primary GA enlargement did not seem to be influenced by a secondary CNV. No association between the intensity of anti-VEGF treatment and changes in atrophy enlargement rates were found. Further studies with larger sample sizes are warranted.
\end{abstract}

Keywords: Age related macular degeneration, Choroidal neovascularization, Geographic atrophy, Optical coherence tomography, Vascular endothelial growth factor

\section{Background}

Severe visual acuity loss is the natural course of late-stage $\mathrm{AMD}$, defined by the development of choroidal neovascularization $(\mathrm{CNV})$, or outer retinal and retinal pigment epithelium geographic atrophy (GA) [1]. Disease dynamics differ strongly between both late manifestations. The neovascular form exhibits a much more aggressive, and GA a markedly slower, but continuously progressing disruption of the retinal architecture, resulting in photoreceptor loss

\footnotetext{
* Correspondence: jakob.siedlecki@med.uni-muenchen.de Department of Ophthalmology, Ludwig-Maximilians-University, Mathildenstrasse 8, 80336 Munich, Germany
}

$[1,2]$. While traditionally neovascular AMD and GA have been regarded as two different cul-de-sacs of drusen deposition, recent research indicates that both entities are much more closely intertwined. Five-year results of the CATT study have shown that $20 \%$ of patients with neovascular AMD under anti-vascular endothelial growth factor (VEGF) therapy develop GA after two years, doubling to $41 \%$ of patients at five years [3]. As a result, today severe vision loss under long-term anti-VEGF therapy is mainly caused by atrophic scars, which contrasts with preanti-VEGF era eyes mainly presenting fibrotic scars [3].

(c) The Author(s). 2021 Open Access This article is licensed under a Creative Commons Attribution 4.0 International License, which permits use, sharing, adaptation, distribution and reproduction in any medium or format, as long as you give appropriate credit to the original author(s) and the source, provide a link to the Creative Commons licence, and indicate if changes were made. The images or other third party material in this article are included in the article's Creative Commons licence, unless indicated otherwise in a credit line to the material. If material is not included in the article's Creative Commons licence and your intended use is not permitted by statutory regulation or exceeds the permitted use, you will need to obtain permission directly from the copyright holder. To view a copy of this licence, visit http://creativecommons.org/licenses/by/4.0/ The Creative Commons Public Domain Dedication waiver (http://creativecommons.org/publicdomain/zero/1.0/) applies to the data made available in this article, unless otherwise stated in a credit line to the data. 
Many risk factors for the development of GA under anti-VEGF therapy have been identified, including partner-eye geographic atrophy $[4,5]$, suggesting that certain AMD phenotypes are especially susceptible to GA [6]. In contrast to these patient-specific risk factors currently not amenable to therapy, excessive anti-VEGF therapy as iatrogenic risk factor has been debated intensely after the 2012 CATT trial finding that patients treated with monthly anti-VEGF had a higher risk of GA as compared to pro-re-nata (PRN) dosing [5].

While almost all published works on the relationship of anti-VEGF and retinal atrophy enrolled patients with neovascular AMD, only two studies have investigated the effects of anti-VEGF in the case of primarily dry, atrophic AMD complicated consequently by $\mathrm{CNV}[7,8]$. Unlike the investigation of atrophy following neovascular AMD and anti-VEGF therapy, eyes with primary GA and secondary $\mathrm{CNV}$ offer the rare opportunity to compare GA enlargement rates before and after the diagnosis of a $\mathrm{CNV}$, and thus study the impact of neovascularization and anti-VEGF therapy on GA. This study was therefore designed to compare GA enlargement rates before and after a secondary neovascular conversion, and to investigate possible associations with the resulting anti-VEGF therapy.

\section{Methods}

\section{Participants}

For this retrospective cohort study, the Smart Eye Database of Munich's University Eye Hospital of Ludwig Maximilians-University, Germany, was screened for patients who were seen with age-related macular degeneration between 2007 and 2015. To study growth speed of GA before and after CNV diagnosis, inclusion criteria for this study were: 1. Diagnosis of AMD; 2. Diagnosis of geographic atrophy due to AMD without any signs of active or previous CNV on OCT and FAG/ICGA; 3. Lack of confounding comorbidities (diabetic retinopathy, hereditary retinal disease, diseases of the vitreoretinal interface, status after vitrectomy, optic media impeding sufficient image quality); 4 . Follow-up $>2$ years. As defined by Lois et al. [9], GA was defined as a reduced signal in both blue autofluorescence (BAF) and nearinfrared reflectance (NIR) covering an area of $>0.05$ $\mathrm{mm}^{2}$ without any confounding caused by hemorrhage, exudate, or blockage of the AF/NIR due to subretinal CNV. Institutional review board (University Eye Hospital Munich, Ludwig-Maximilians-University Munich) approval was obtained for this retrospective chart review. All patients provided informed consent prior to the first treatment, and the study adhered to the tenets of the Declaration of Helsinki.

Epidemiological data from all patients was gathered, including age, gender, ocular comorbidities, previous procedures, date of first diagnosis of GA due to AMD, date of first $\mathrm{CNV}$ diagnosis and anti-VEGF injection, number and type of anti-VEGF injections, and objective refraction-based visual acuity at baseline, date of CNV diagnosis, and end of follow-up using an ETDRS chart in a distance of $4 \mathrm{~m}$.

\section{Multimodal imaging}

Multimodal imaging was performed as needed at each visit after pupil dilation as described previously [10]. At each visit, spectral domain optical coherence tomography (SD-OCT) in volume mode (49 B-scans covering an area of $6 \times 6 \mathrm{~mm}$ centered on the fovea), near-infrared (NIR)/ blue autofluorescence (BAF) confocal laser scanning ophthalmoscopy (CSLO) were performed. and fluorescein (FAG) and indocyanine green (ICG) angiography at baseline, when $\mathrm{CNV}$ was suspected and when CNV activity was uncertain (all on Spectralis HRA + OCT, Heidelberg Engineering, Heidelberg, Germany).

Geographic atrophy size was documented on blue autofluorescence CSLO images obtained at $488 \mathrm{~nm}$ excitation $\left(30^{\circ} \times 30^{\circ} ; 768 \times 768\right.$ pixels; high speed mode). Quantification was performed using the area measurement tool in the Heidelberg Engineering proprietary analysis software (Heyex) by two experienced readers (JS and CK). The interclass correlation coefficient (ICC) between both readers was 0.98 (95\% confidence interval: 0.97-0.99).

\section{Anti-VEGF treatment}

$\mathrm{CNV}$ activity was defined on OCT as (I) any new macular fluid, (II) pigment epithelium detachment (PED) increasing central macular thickness $>50 \mu \mathrm{m}$, or (III) new or increasing macular hemorrhage. On FAG/ICGA, $\mathrm{CNV}$ activity was defined as exudation increasing with time. In case of newly diagnosed or reactivated CNV, intravitreal anti-VEGF injections were given using a prore-nata regimen. Substances used included ranibizumab (Novartis Pharma AG, Basel, Switzerland), aflibercept (Bayer Healthcare Pharmaceuticals, Berlin, Germany) and off-label bevacizumab (Genentech Inc., South San Francisco, CA, USA, and Hofmann-La Roche Ltd., Basel Switzerland). Treatment was stopped in the case of successful fluid elimination, and re-initiated when $\mathrm{CNV}$ reactivation was observed as defined above.

\section{Statistical analysis}

Data were collected and analyzed in Microsoft Excel (Microsoft, Redmond, WA, USA). SPSS Statistics 23 (SPSS Inc., Chicago, IL, USA) was used for statistical analysis. The level to indicate statistical significance was defined as $p<0.05$. The agreement of GA area measured by both readers was calculated as interclass correlation coefficient. The Shapiro-Wilk test was employed to test for normal distribution of the measured parameters 
within the study group. The Wilcoxon signed rank and the dependent samples t-test were employed to test for significant differences during follow-up within study and partner eyes. The Wilcoxon signed rank and the independent samples t-test were used for the comparison of study and partner eyes. Pearson's correlation coefficient was used to test associations of dependent and independent variables. Graphs were plotted in Microsoft Excel showing the mean \pm standard deviation.

\section{Results}

\section{Baseline parameters}

Out of 1632 eyes presenting with a dry atrophic macula between 2007 and 2015, 522 eyes with geographic atrophy (GA) due to age-related macular degeneration without significant other comorbidities were identified. After exclusion of patients with a follow-up $<2$ years and the wrong sequence of events, i.e. GA secondary to neovascular AMD, six patients who presented with GA prior to $\mathrm{CNV}$ were identified. Out of these 12 eyes, two eyes of two patients suffered from submacular hemorrhage and fibrosis in the follow-up, which did not allow for sufficient imaging. Thus, 10 eyes of six patients were included in the study. There were six study eyes with the GA-CNV sequence and 4 partner eyes with sole GA acting as an intra-individual comparison group.

Detailed baseline parameters of the study cohort can be found in Table 1. In brief, mean age of the six patients was $76.8 \pm 2.0$ (range: $72-79$ ) years. Total followup was $5.06 \pm 3.01(2.01-9.68)$ years, split up into $1.42 \pm$ $0.48(0.77-1.80)$ years before and $3.64 \pm 2.73(1.15-7.88)$ years after CNV diagnosis. All eyes (100\%) had subretinal drusenoid deposits (SDD) at baseline, while 5/10 (50\%) also had soft macular drusen. All eyes (100\%) showed hyperautofluorescence surrounding the GA area, of which $5(50 \%)$ showed a banded, four (40\%) a diffuse, and one (10\%) a diffuse trickling phenotype as classified previously [11]. CNV were type 2 in all cases, with foveal involvement in 4 eyes (67\%) and intraretinal fluid in all cases. A patient example can be found in Fig. 1.

\section{GA growth rate}

For the six study eyes, a GA at baseline of $2.11 \pm 1.48$ $(0.79-4.35) \mathrm{mm}^{2}$ increased significantly to $4.55 \pm 2.98$ $(2.31-10.51) \mathrm{mm}^{2}$ at $\mathrm{CNV}$ diagnosis $(p=0.03)$ and $8.58 \pm 3.50(4.37-14.07) \mathrm{mm}^{2}(p=0.004)$ at end of follow-up (Fig. 2a). Resulting total GA growth speed was $1.47 \pm 0.82(0.77-3.03) \mathrm{mm}^{2} /$ year. There was no significant difference between mean growth speed pre-CNV $\left(1.58 \pm 0.99(0.68-3.46) \mathrm{mm}^{2} /\right.$ year $)$ and after CNV $\left(1.39 \pm 0.65(0.80-2.49) \mathrm{mm}^{2} /\right.$ year; $\left.p=0.44\right)$. As classified by Holz et al. [11], three of the study eyes had a banded autofluorescence phenotype, two a diffuse and one a diffuse-trickling phenotype. The fastest
Table 1 Patient demographic and baseline lesion data with GA enlargement characteristics

\begin{tabular}{|c|c|}
\hline No. of eyes (n) & 10 \\
\hline No. of patients (n) & 6 \\
\hline Gender (m/f) & $0 / 6$ \\
\hline Mean age (y) & $77 \pm 2$ (range: 75 to 79$)$ \\
\hline Mean follow-up (years) & $5.06 \pm 3.01(2.01-9.68)$ \\
\hline before CNV diagnosis & $1.42 \pm 0.48(0.77-1.80)$ \\
\hline after CNV diagnosis & $3.64 \pm 2.73(1.15-7.88)$ \\
\hline \multicolumn{2}{|l|}{ Mean BCVA (logMAR) } \\
\hline \multicolumn{2}{|l|}{ Study eye $(n=6)$} \\
\hline baseline & $0.84 \pm 0.40(0.30-1.30)$ \\
\hline at CNV diagnosis & $0.94 \pm 0.44(0.30-1.40)$ \\
\hline end of follow-up & $1.01 \pm 0.57(0.40-1.92)$ \\
\hline \multicolumn{2}{|l|}{ Partner eye $(n=4)$} \\
\hline baseline & $1.09 \pm 0.56(0.50-2.00)$ \\
\hline end of follow-up & $1.24 \pm 0.48(0.50-2.00)$ \\
\hline \multicolumn{2}{|l|}{ Drusen } \\
\hline Soft & $5 / 10(50 \%)$ \\
\hline SDD & 10/10 (100\%) \\
\hline \multicolumn{2}{|l|}{ Choroidal thickness } \\
\hline \multicolumn{2}{|l|}{ Study eye } \\
\hline baseline $(\mu \mathrm{m})$ & $152 \pm 51(71-224)$ \\
\hline last follow-up ( $\mu \mathrm{m})$ & $101 \pm 44(39-165)$ \\
\hline \multicolumn{2}{|l|}{ Partner eye } \\
\hline baseline $(\mu \mathrm{m})$ & $130 \pm 63(46-222)$ \\
\hline last follow-up ( $\mu \mathrm{m})$ & $127 \pm 99(23-290)$ \\
\hline \multicolumn{2}{|l|}{ Geographic atrophy } \\
\hline \multicolumn{2}{|l|}{ Study eye $(n=6)$} \\
\hline GA lesions baseline ( $n$ ) & $2 \pm 1(1-4)$ \\
\hline Foveal involvement & $4 / 6(66.7 \%)$ \\
\hline \multicolumn{2}{|l|}{ Phenotype } \\
\hline Banded & $3 / 6(50 \%)$ \\
\hline Diffuse & $2 / 6(33.3 \%)$ \\
\hline Diffuse Trickling & $1 / 6(16.7 \%)$ \\
\hline GA baseline $\left(\mathrm{mm}^{2}\right)$ & $2.11 \pm 1.48(0.79-4.35)$ \\
\hline GA CNV diagnosis $\left(\mathrm{mm}^{2}\right)$ & $4.55 \pm 2.98(2.31-10.51)$ \\
\hline GA last follow-up (mm²) & $8.58 \pm 3.50(4.37-14.07)$ \\
\hline
\end{tabular}

total growth speed (up to $3.46 \mathrm{~mm}^{2} /$ year) was exhibited by the only eye with a diffuse-trickling phenotype, while the slowest growth was observed in one of the eyes with a banded phenotype $\left(0.68 \mathrm{~mm}^{2} /\right.$ year $)$. Mean growth speed ratio for each eye (calculated as growth rate post-CNV/pre-CNV) was $0.97 \pm 0.30$ (0.59-1.40). All lesions diagnosed were type II CNVs 


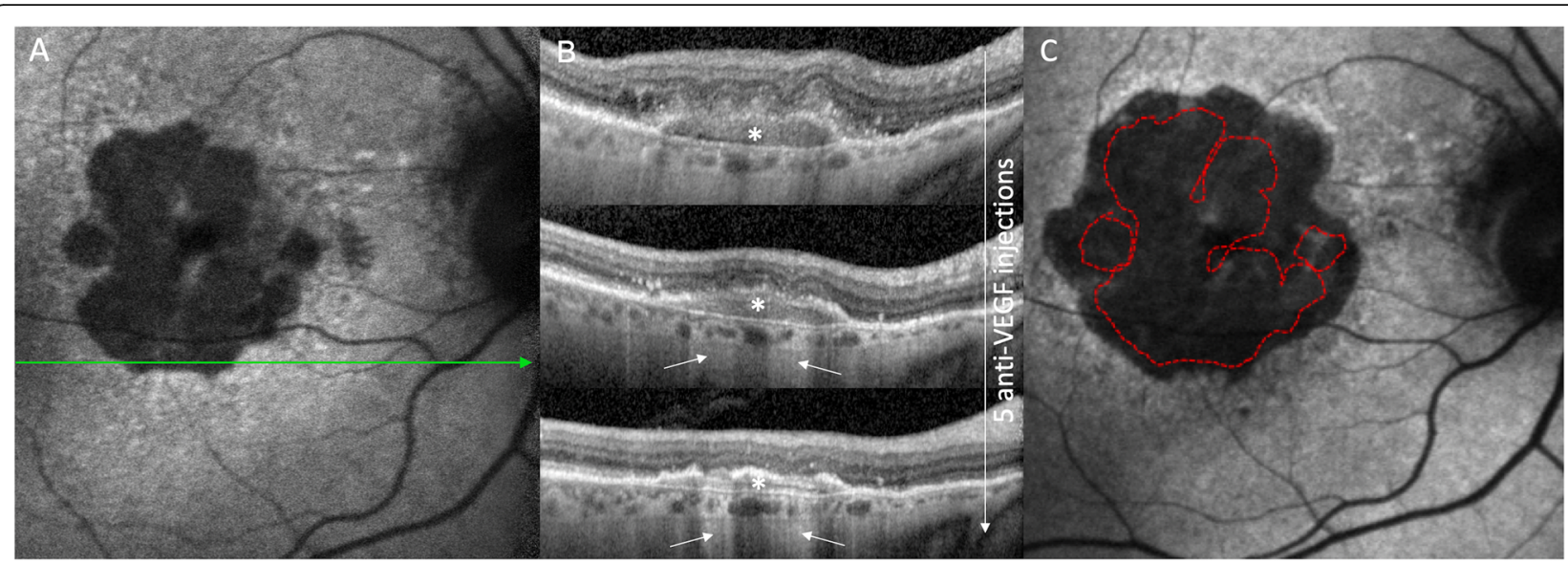

Fig. 1 Patient example of primary geographic atrophy (GA) due to age-related macular degeneration complicated by the development of a choroidal neovascularization (CNV). Fourteen months after the baseline exam (a), a type 2 choroidal neovascularization (white *) was diagnosed on the lower border of the GA (b) and successfully treated with three monthly anti-VEGF injections. Due to reactivation, two further anti-VEGF injections were given, resulting in a morphologically partially fibrotic PED. On OCT, the areas of hypertransmission increased during follow-up. At the end of follow-up 21 months after the last anti-VEGF injection (c), the GA had considerably enlarged more in the three directions (nasally, temporally, superiorly) not affected by the CNV (lower aspect of GA)

with intraretinal fluid during follow-up. Foveal involvement was seen in $4 / 6(67 \%)$ eyes. In two eyes (33.3\%), the CNV was adjacent to the GA and slowed growth in this area was observed.

\section{Comparison of study and partner eye GA growth rate}

For the four partner eyes, which did not show any signs of active CNV during follow-up, mean GA area at baseline was $2.01 \pm 1.19(0.24-2.77) \mathrm{mm}^{2}$, which was not different from the four corresponding study eyes $(2.47 \pm$ $\left.1.73(0.79-4.35) \mathrm{mm}^{2}\right)$. Enlarging to $8.74 \pm 3.64(5.67-$ 13.29) $\mathrm{mm}^{2}$ at end of follow-up, the resulting total growth speed of partner eyes was $1.76 \pm 1.11(0.94-3.40)$ $\mathrm{mm}^{2} /$ year, which was not statistically different $(p=0.86)$ from the four corresponding study eyes $(1.63 \pm 0.99$ (0.77-3.03). A correlation of study and partner eye growth rates can be found in Fig. $3 \mathrm{~B}$.

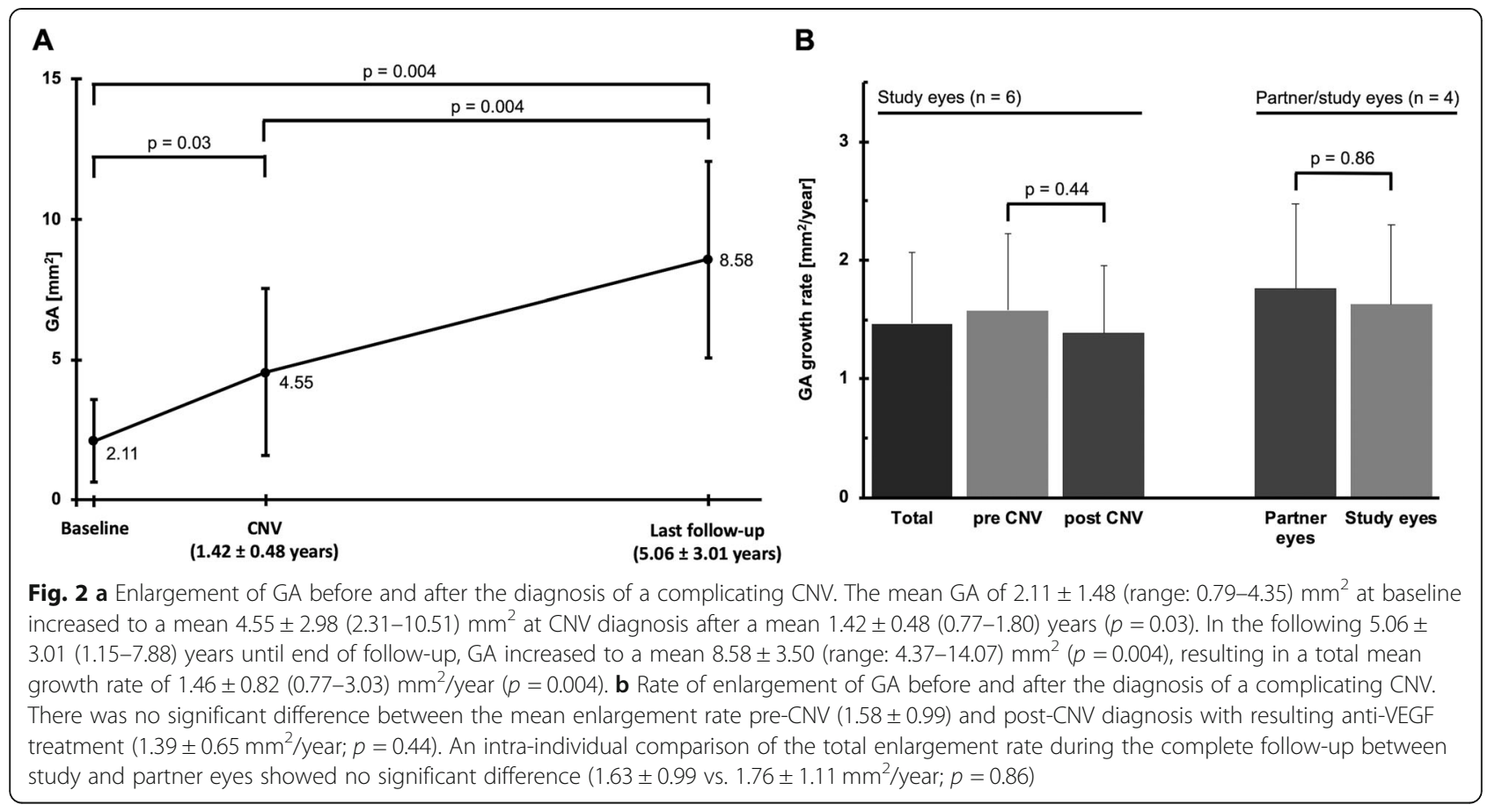




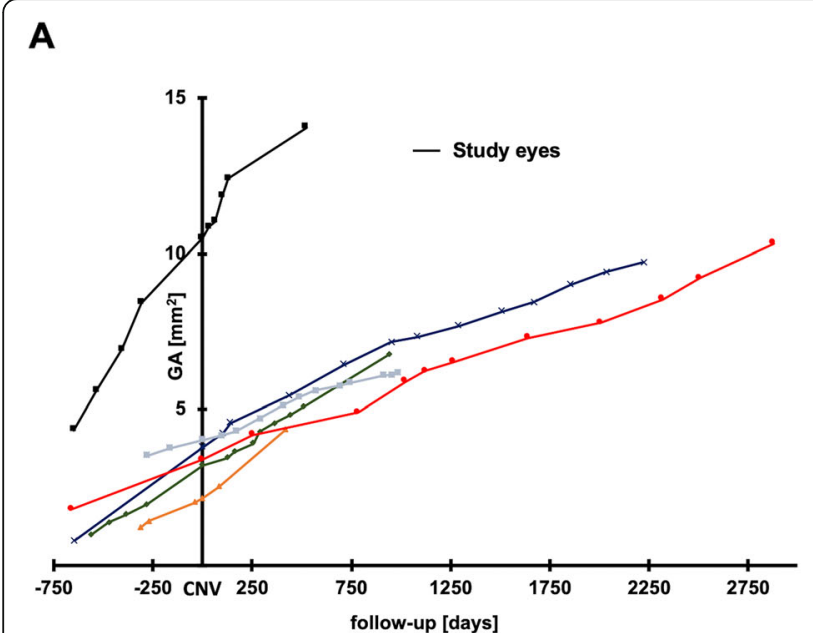

B

Fig. 3 a Individual growth rates pre/post CNV for the six study eyes. Growth rate ratios ranged from 0.59 to 1.40, calculated as growth rate post/ pre CNV. $\mathbf{b}$ Comparison of GA growth rates pre- and post-CNV between study eyes and partner eyes without signs of CNV (dotted lines). No significant difference in growth rate was observed $\left(1.63 \pm 0.99(0.77-3.03)\right.$ vs. $1.76 \pm 1.11(0.94-3.40) \mathrm{mm}^{2} /$ year; $\left.p=0.86\right)$

\section{Correlation of GA growth rate and anti-VEGF injections} Over the mean time of $3.64 \pm 2.73$ years with CNV diagnosis, a mean of $8.3 \pm 2.8(5-13)$ anti-VEGF injections were given. Of the 50 anti-VEGF injections in total, 27 were aflibercept (54\%), 20 ranibizumab (40\%) and 3 bevacizumab (6\%). For 37 out of 50 injections (74\%), new or increasing intraretinal fluid (IRF) associated with the $\mathrm{CNV}$ was the reason for treatment; the remaining 13 injections $(26 \%)$ were performed due to new subretinal fluid.

Associations of change in growth speed with baseline and treatment parameters can be found in Table 2. Pearson correlation showed no connection between post$\mathrm{CNV}$ growth speed acceleration and the total amount of anti-VEGF injections given $(\mathrm{r}=0.58 ; p=0.23$; Fig. $4 \mathrm{a})$ or the amount of mean anti-VEGF injections per year $(\mathrm{r}=$ $0.52 ; p=0.30$ ). Besides, no other investigated factor was found to be relevant (baseline GA size: $\mathrm{r}=-0.06, p=$ 0.91; number of baseline GA lesions: $\mathrm{r}=0.45, p=0.38$; subfoveal choroidal thickness: $\mathrm{r}=-0.26, p=0.62$; age: $\mathrm{r}=-0.04, p=0.94$; number of visits with IRF presence: $\mathrm{r}=-0.44, p=0.38$ ). Figure $4 \mathrm{~b}$ shows the change in GA growth speed pre-/post-CNV for each eye stratified by anti-VEGF injection number.

In the study eyes, visual acuity of $0.84 \pm 0.40(0.30$ 1.30) $\log$ MAR at baseline remained stable at CNV diagnosis $(0.94 \pm 0.44(0.30-1.40) ; p=0.39)$ and end of follow-up $(1.01 \pm 0.57(0.40-1.92) ; p=0.71)$.

\section{Discussion}

Various risk factors for GA have been described, including SDD [12, 13], IRF [14, 15], reduced subfoveal choroidal thickness $[14,16]$ and age [17]. While these factors currently largely remain inaccessible to therapy, atrophy and atrophic scars can also result from CNV activity [18], which can be successfully managed by intravitreal anti-VEGF treatment. However, retrospective analyses of large clinical trials, including CATT [5] and IVAN [19],

Table 2 Correlation of baseline factors influencing change of growth speed after CNV diagnosis

\begin{tabular}{|c|c|c|c|c|c|c|c|c|}
\hline \multirow{2}{*}{$\begin{array}{l}\text { Study Eye } \\
1\end{array}$} & \multicolumn{3}{|c|}{$\begin{array}{l}\text { GA growth speed }\left(\mathrm{mm}^{2} /\right. \\
\text { year) } \\
\text { ratio } \\
\text { pre post post/pre }\end{array}$} & \multirow{2}{*}{$\begin{array}{l}\text { Baseline } \mathrm{GA}\left(\mathrm{mm}^{2}\right) \\
\\
0.79\end{array}$} & \multirow{2}{*}{$\begin{array}{l}\text { Baseline GA lesions ( } \mathbf{n} \text { ) } \\
1\end{array}$} & \multirow{2}{*}{$\begin{array}{l}\text { Baseline choroid }(\mu \mathrm{m}) \\
71\end{array}$} & \multirow{2}{*}{$\begin{array}{l}\text { IRF presence (\%) } \\
0.21\end{array}$} & \multirow{2}{*}{$\begin{array}{l}\text { Anti-VEGF } \\
\text { IVOM (n) } \\
6\end{array}$} \\
\hline & 1.70 & 0.97 & 0.59 & & & & & \\
\hline 2 & 3.46 & 2.49 & 0.72 & 4.35 & 1 & 154 & 0.22 & 5 \\
\hline 3 & 0.89 & 0.88 & 0.99 & 1.79 & 4 & 127 & 0.44 & 8 \\
\hline 4 & 0.68 & 0.80 & 1.17 & 3.52 & 1 & 165 & 0.36 & 9 \\
\hline 5 & 1.28 & 1.79 & 1.40 & 1.22 & 3 & 172 & 0.93 & 9 \\
\hline 6 & 0.85 & 1.65 & 0.94 & 1.20 & 3 & 224 & 0.31 & 13 \\
\hline \multicolumn{4}{|c|}{$\begin{array}{l}\text { Pearson correlation coefficient (r) with } \\
\text { change in growth speed of GA }\end{array}$} & $\begin{array}{l}-0.06 \\
p=0.91\end{array}$ & $\begin{array}{l}0.45 \\
p=0.38\end{array}$ & $\begin{array}{l}-0.26 \\
p=0.62\end{array}$ & $\begin{array}{l}-0.44 \\
p=0.38\end{array}$ & $\begin{array}{l}0.58 \\
p=0.23\end{array}$ \\
\hline
\end{tabular}



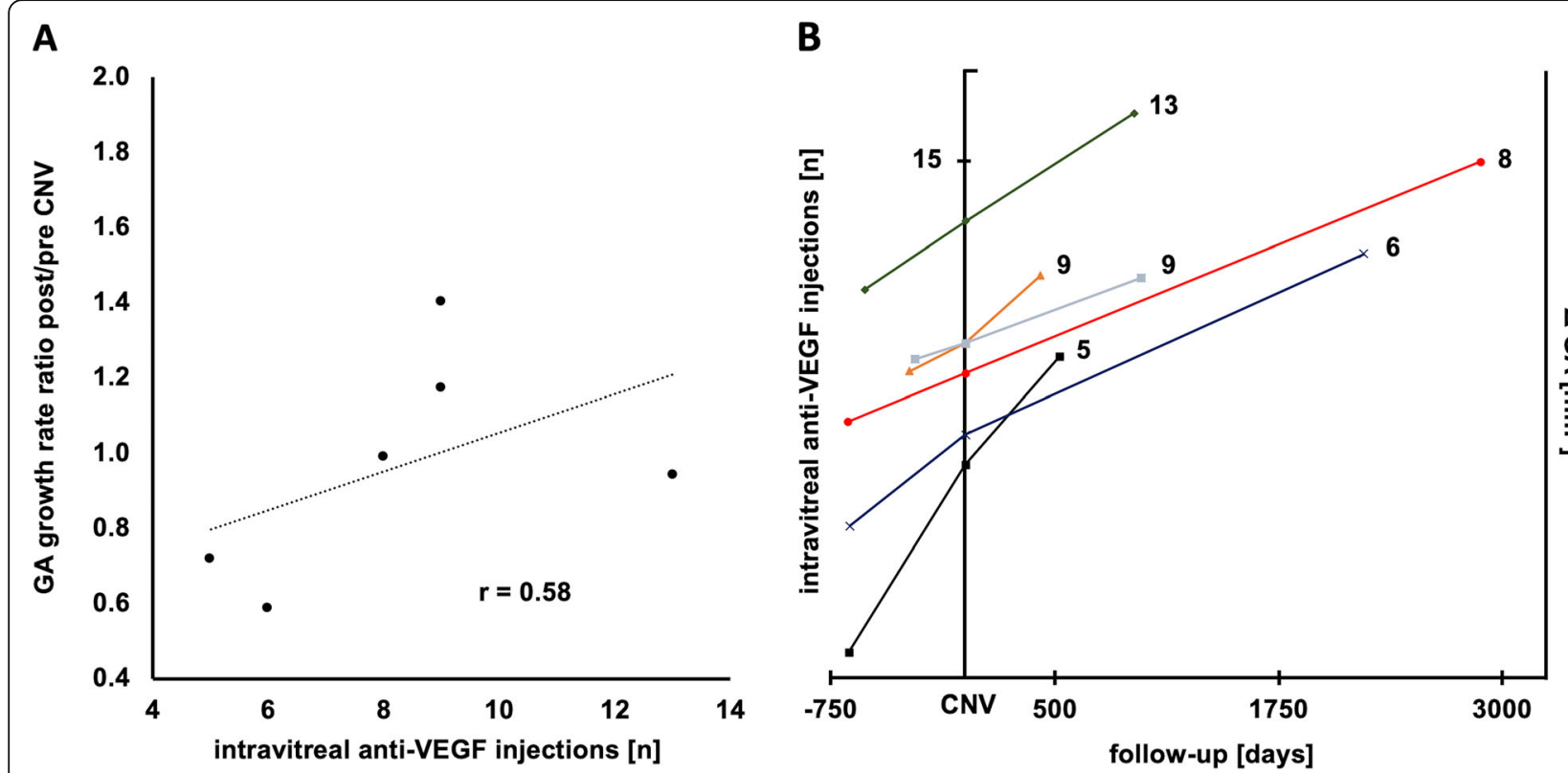

Fig. 4 a Change in GA enlargement rate correlated with the total amount of anti-VEGF injections given. Change in enlargement speed was defined as the ratio of growth rate after CNV diagnosis until end of follow-up, divided by the growth rate prior to CNV diagnosis. Pearson correlation revealed no connection between changes in growth rate and the total or yearly amount of anti-VEGF injections given (total: $r=0.58 ; p=0.23 ;$ yearly: $r=0.52 ; p=$ 0.30). Besides, no other investigated factor was found to be relevant (baseline GA size: $r=-0.06, p=0.91$; number of baseline GA lesions: $r=0.45, p=$ 0.38; subfoveal choroidal thickness: $r=-0.26, p=0.62$; age: $r=-0.04, p=0.94$; number of visits with IRF presence: $r=-0.44, p=0.38)$. b Individual study eye growth rates pre- and post-CNV in $\mathrm{mm}^{2} /$ year ( $\mathrm{x}$-axis and right $\mathrm{y}$-axis) stratified by anti-VEGF injection number on the left $y$-axis. Higher cumulative anti-VEGF injection count did not correlate with growth rate acceleration

and smaller prospective studies [20] have suggested that excess anti-VEGF treatment, i.e. "drying the macula to excessively", might increase the risk for GA and drive GA enlargement.

Almost exclusively all studies on the topic of GA and anti-VEGF have examined GA secondary to neovascular AMD. In contrast to studying nascent GA as a response to anti-VEGF, measuring the effect of anti-VEGF on a pre-existent GA offers the unique opportunity to validate a possible toxicity directly on well-established lesions with the corresponding pre-CNV growth rates acting as a valid intra-eye control group. In our study analyzing primary GA lesions that secondarily developed CNV and required anti-VEGF treatment, there was no significant difference between mean growth rate before $\mathrm{CNV}$ $\left(1.58 \pm 0.99(0.68-3.46) \quad \mathrm{mm}^{2} /\right.$ year $)$ and after CNV $\left(1.39 \pm 0.65(0.80-2.49) \mathrm{mm}^{2} /\right.$ year $)$, resulting in a post/ pre $\mathrm{CNV}$ enlargement ratio of 0.97 . Moreover, there was no difference in enlargement rate between eyes developing $\mathrm{CNV}$ and their associated partner eyes. And strikingly, no correlation between the amount of anti-VEGF injections applied for $\mathrm{CNV}$ treatment and changes in GA enlargement rates were found, while the GA growth rate was $1.47 \pm 0.82(0.77-3.03) \mathrm{mm}^{2} /$ year, which is well in line with the literature reporting mean 0.53 to 2.6 $\mathrm{mm}^{2} /$ year with a median of approximately $1.78 \mathrm{~mm}^{2}$ / year [21].
These data suggest that exudative CNV development, if treated accordingly, and subsequent anti-VEGF treatment seem to represent secondary factors influencing GA with a much lesser impact than "genetically coded" risk factors, e.g. SDD, choroidal thinning, and age. Due to the presence of SDD in all eyes in our study, rather severe choriocapillary ischemia and thus stronger susceptibility for GA and faster enlargement rates could be assumed, with little secondary influence of a newly diagnosed exudative $\mathrm{CNV}$.

In contrast to these data, a growing body of evidence suggests that type $1 \mathrm{CNV}$ might protect overlying retinal areas from GA growth [22]. Due to the availability of OCT angiography, CNV presence can nowadays be frequently detected even in the absence of leakage, a finding which has been termed 'quiescent $\mathrm{CNV}$ ' by many authors [23] and reproduces earlier histopathologic findings, which suggested subclinical CNV in up to $33 \%$ of eyes presenting with solely GA clinically [23]. Recently, de Oliveira Dias and colleagues found that most eyes with dry AMD developing exudation during follow-up already had quiescent non-exudative $\mathrm{CNV}$ at baseline [24]. In this scenario, the current aim of anti-VEGF therapy might be to restore and preserve an "anti-VEGF" equilibrium, in which exudative changes due to $\mathrm{CNV}$ are treated with repeat injections, and type $2 \mathrm{CNVs}$ are pruned into mature type 1 lesions. Such trophic type 1 
lesions can then persist in a non-exudative state and provide metabolic support to the RPE and retina, being tolerated as long as exudation is absent, and retreated with anti-VEGF when exudation and invasive growth recur.

As a limitation, our study does not provide OCT angiography imaging, which might have detected or excluded quiescent $\mathrm{CNV}$ at the time of inclusion. Moreover, a major limitation of our study certainly lies within its small sample size, which however results from the investigation of a rare, but very specific phenotypic presentation of AMD. Our study also lacked a defined follow-up schedule to have the possibility to begin intravitreal treatment promptly and thus improve comparability between eyes.

\section{Conclusion}

In conclusion, our small pilot study suggests that primary GA enlargement rates are largely independent from complicating secondary $\mathrm{CNV}$ development and the resulting anti-VEGF therapy. In the ongoing debate on the relationship of anti-VEGF therapy and macular atrophy, this offers further reassurance to also perform antineovascular treatments in mainly atrophic lesion types. Due to the possibly protective effects of stable type 1 $\mathrm{CNV}$, prevention of type 2 conversion and exudation might be the main therapy goal in this particular phenotype of AMD, while non-exudative type 1 lesions can be allowed to persist in a non-exudative trophic state. Further studies with a larger sample size are warranted.

\section{Abbreviations \\ AMD: Age-related macular degeneration; BAF: Blue autofluorescence; CNV: Choroidal neovascularization; CSLO: Confocal laser scanning ophthalmoscopy; FAG: Fluorescein angiography; GA: Geographic atrophy; ICC: Interclass correlation coefficient; ICGA: Indocyanine green angiography; IRF: Intraretinal fluid; MA: Macular atrophy; OCT: Optical coherence tomography; SDD: Subretinal drusenoid deposits; VEGF: Vascular endothelial growth factor}

\section{Acknowledgments}

The data of this study, including its abstract, were presented at the 117th annual congress of the German Society of Ophthalmology (DOG) in Berlin in September 2019 [25].

\section{Authors' contributions}

JS, CK, and BS performed multimodal imaging analysis. JS, CK, RL, TK, KK and RS, SP and AW interpreted the data. JS created the graphs. JS drafted the manuscript. JS, CK, BS, RL, TK, KK, RS, SP and AW developed the manuscript into its final version. The authors have read and approved the manuscript.

\section{Funding}

None. Open Access funding enabled and organized by Projekt DEAL.

\section{Availability of data and materials}

The datasets during and/or analysed during the current study available from the corresponding author on reasonable request.

\section{Ethics approval and consent to participate}

Institutional review board (University Eye Hospital Munich, Ludwig-

Maximilians-University Munich) approval was obtained for this retrospective chart review, and the study adhered to the tenets of the Declaration of Helsinki. All patients provided written consent.

\section{Consent for publication}

None applicable, as no uniquely identifying information about a single subject are given.

\section{Competing interests}

No author reports any financial interest relevant to this study.

Jakob Siedlecki received previous speaker fees and travel expenses from Novartis Pharma GmbH, Carl Zeiss Meditec AG, Oculentis OSD Medical $\mathrm{GmbH}$ and Pharm-Allergan $\mathrm{GmbH}$. Jakob Siedlecki received personal consultation fees from Bayer AG.

Benedikt Schworm received previous speaker fees and travel expenses from Novartis Pharma GmbH and Topcon Corporation.

Thomas C Kreutzer received previous speaker fees from Alcon Pharma

$\mathrm{GmbH}$. Thomas $\mathrm{C}$ Kreutzer received personal consultation fees from Novartis Pharma GmbH and Bayer AG. Thomas C Kreutzer received travel reimbursement from D.O.R.C. (International) B.V.

Raffael Liegl received previous speaker fees from Novartis Pharma GmbH. Karsten Kortuem received previous speaker fees and/or travel expenses from Novartis Pharma GmbH, Bayer AG, and Alcon Pharma GmbH. Karsten Kortüm received personal consultation fees from Big Picture Medical. Karsten Kortüm received travel expenses from Pharm-Allergan $\mathrm{GmbH}$ and Heidelberg Engineering $\mathrm{GmbH}$.

Ricarda Schumann received previous speaker fees and travel expenses from Bayer AG, Novartis Pharma GmbH, Pharm-Allergan GmbH, Heidelberg Engineering $\mathrm{GmbH}$, and Carl Zeiss Meditec AG.

Siegfried Priglinger received previous speaker fees and/or travel expenses from Novartis Pharma GmbH, Oertli AG, Bayer AG, Alcon Pharma GmbH and Pharm-Allergan $\mathrm{GmbH}$.

Armin Wolf received previous speaker fees and research funds from Novartis Pharma GmbH, Oertli AG, Bayer AG, Pharm-Allergan GmbH and Alimera Sciences Ophthalmologie $\mathrm{GmbH}$.

Received: 6 May 2020 Accepted: 14 December 2020

Published online: 05 January 2021

References

1. Mitchell P, Liew G, Gopinath B, Wong TY. Age-related macular degeneration. Lancet. 2018;392(10153):1147-59.

2. Holz FG, Strauss EC, Schmitz-Valckenberg S, van Lookeren Campagne M. Geographic atrophy: clinical features and potential therapeutic approaches. Ophthalmology. 2014;121(5):1079-91.

3. Maguire MG, Martin DF, Ying GS, et al. Five-year outcomes with antivascular endothelial growth factor treatment of Neovascular age-related macular degeneration: the comparison of age-related macular degeneration treatments trials. Ophthalmology. 2016;123(8):1751-61.

4. Sadda SR, Tuomi LL, Ding B, Fung AE, Hopkins JJ. Macular atrophy in the HARBOR study for Neovascular age-related macular degeneration. Ophthalmology. 2018;125(6):878-86.

5. Grunwald JE, Daniel E, Huang J, et al. Risk of geographic atrophy in the comparison of age-related macular degeneration treatments trials. Ophthalmology. 2014;121(1):150-61.

6. Sakurada Y, Yoneyama S, Sugiyama A, et al. Prevalence and genetic characteristics of geographic atrophy among elderly Japanese with agerelated macular degeneration. PLoS One. 2016;11(2):e0149978.

7. Amaro $\mathrm{MH}$, Roller $\mathrm{AB}$. Intravitreal ranibizumab and bevacizumab therapy for choroidal neovascularization in age-related macular degeneration with extensive pre-existing geographic atrophy. Arq Bras Oftalmol. 2012;75(4): 273-6.

8. Querques G, Massamba N, Coscas F, Forte R, Souied EH. Choroidal neovascularisation complicating geographic atrophy in age-related macular degeneration. Br J Ophthalmol. 2012;96(12):1479-83.

9. Lois N, McBain V, Abdelkader E, Scott NW, Kumari R. Retinal pigment epithelial atrophy in patients with exudative age-related macular degeneration undergoing anti-vascular endothelial growth factor therapy. Retina (Philadelphia, Pa). 2013;33(1):13-22.

10. Siedlecki J, Fischer C, Schworm B, et al. Impact of sub-retinal fluid on the long-term incidence of macular atrophy in Neovascular age-related macular 
degeneration under Treat \& Extend Anti-Vascular Endothelial Growth Factor Inhibitors. Sci Rep. 2020;10(1):8036.

11. Holz FG, Bindewald-Wittich A, Fleckenstein M, Dreyhaupt J, Scholl HP, Schmitz-Valckenberg S. Progression of geographic atrophy and impact of fundus autofluorescence patterns in age-related macular degeneration. Am J Ophthalmol. 2007;143(3):463-72.

12. Zarubina AV, Gal-Or O, Huisingh CE, Owsley C, Freund KB. Macular atrophy development and subretinal Drusenoid deposits in anti-vascular endothelial growth factor treated age-related macular degeneration. Invest Ophthalmol Vis Sci. 2017;58(14):6038-45.

13. Spaide RF, Ooto S, Curcio CA. Subretinal drusenoid deposits AKA pseudodrusen. Surv Ophthalmol. 2018;63(6):782-815.

14. Kuroda Y, Yamashiro K, Ooto S, et al. Macular atrophy and macular morphology in aflibercept-treated neovascular age-related macular degeneration. Retina (Philadelphia, Pa). 2018;38(9):1743-50.

15. Munk MR, Ceklic L, Ebneter A, Huf W, Wolf S, Zinkernagel MS. Macular atrophy in patients with long-term anti-VEGF treatment for neovascular age-related macular degeneration. Acta Ophthalmol. 2016;94(8):e757-64.

16. Fan W, Abdelfattah NS, Uji A, et al. Subfoveal choroidal thickness predicts macular atrophy in age-related macular degeneration: results from the TREX-AMD trial. Graefe's Arch Clin Exper Ophtha= Albrecht von Graefes Archiv fur klinische und experimentelle Ophthalmologie. 2018;256(3):511-8.

17. Thavikulwat AT, Jacobs-El N, Kim JS, et al. Evolution of geographic atrophy in participants treated with Ranibizumab for Neovascular age-related macular degeneration. Ophthalmol Retina. 2017;1 (1):34-41.

18. Sarks J, Tang K, Killingsworth M, Arnold J, Sarks S. Development of atrophy of the retinal pigment epithelium around disciform scars. Br J Ophthalmol. 2006;90(4):442-6.

19. Chakravarthy U, Harding SP, Rogers CA, et al. Alternative treatments to inhibit VEGF in age-related choroidal neovascularisation: 2-year findings of the IVAN randomised controlled trial. Lancet (London, England). 2013; 382(9900):1258-67.

20. Schutze C, Wedl M, Baumann B, Pircher M, Hitzenberger CK, Schmidt-Erfurth U. Progression of retinal pigment epithelial atrophy in antiangiogenic therapy of neovascular age-related macular degeneration. Am J Ophthalmol. 2015;159(6):1100-1114.e1101.

21. Fleckenstein M, Mitchell P, Freund KB, et al. The progression of geographic atrophy secondary to age-related macular degeneration. Ophthalmology. 2018:125(3):369-90.

22. Dhrami-Gavazi E, Balaratnasingam C, Lee W, Freund KB. Type 1 neovascularization may confer resistance to geographic atrophy amongst eyes treated for neovascular age-related macular degeneration. Int I Retina Vitreous. 2015;1:15.

23. Sarks SH. Ageing and degeneration in the macular region: a clinicopathological study. Br J Ophthalmol. 1976;60(5):324-41.

24. de Oliveira Dias JR, Zhang Q, Garcia JMB, et al. Natural history of subclinical neovascularization in nonexudative age-related macular degeneration using swept-source OCT angiography. Ophthalmology. 2018;125(2):255-66.

25. Siedlecki J. Abstractband DOG 2019. Ophthalmologe. 2019;116(2):25-218.

\section{Publisher's Note}

Springer Nature remains neutral with regard to jurisdictional claims in published maps and institutional affiliations.

Ready to submit your research? Choose BMC and benefit from:

- fast, convenient online submission

- thorough peer review by experienced researchers in your field

- rapid publication on acceptance

- support for research data, including large and complex data types

- gold Open Access which fosters wider collaboration and increased citations

- maximum visibility for your research: over $100 \mathrm{M}$ website views per year

At $\mathrm{BMC}$, research is always in progress.

Learn more biomedcentral.com/submissions 